\title{
RESPONDING TO OBSCENITY: \\ METHODOLOGICAL AND CONCEPTUAL PROBLEMS
}

by

STEVEN TURNER

University of Missouri-Columbia

It has been held from two-viewpoints, the socio-cultural

and the psychoanalytic, that anxiety responses to obscene stimuli indicate sexual frustration. To test this hypothesis, a model of the responding individual is advanced, and the individual, stimuli, and responses are discussed in terms of it. Two sociologically similar groups of student men, one substantially deprived of women, were asked to respond to twenty stimuli of four types: non-sexual deviant, non-sexual non-deviant, sexual non-deviant, and sexual deviant. Deprived students showed significantly less anxiety in response to the "sexual deviant" stimuli, disconfirming the hypothesis. It is speculated that this may result from exposure to middle-brow feminine culture. The changing nature of sexual culture is discussed and these changes are explained in relation to pornography and obscenity.

The notion that people with illiberal political views or cultural traits, who seem intolerant and parochial are suffering from a personality disorder or other psychic afflictions has proved to be a "hardy perennial" of social science's garden of follies. The notion is virtually ubiquitous, judging by the variety of forms it has taken, from attacks on Birchers to attacks on student radicals, and by the level of popular discourse to which it has descended. The main role the idea has had since the early 1940's is as a seemingly sophisticated (but entirely ad hominem) argument against various political or cultural positions. The ideological biases of the scientific "justification" of the argument have been pointed out (Shils, 1954) without discernible effect of its continued utilization.1

In recent years, with the controversies over sex education and obscenity in art and literature, an early variant on this basic theme has been resurrected: the proposition that strong reactions to sexual or obscene stimuli indicate anxiety. stemming from sexual frustration. As sociological conceptions go, this is a view of considerable antiquity. It derives from Neitzsche's examination of Christian ethics, and achieves its most explicit formulation in a comment by Max Scheler that 
the disposition of many old maids, always to inquire into all symptoms of sexuality in their surroundings in order to pass severe judgments of condemnation upon them, is nothing but a vicarious form of sexual gratification, disguised as the gratification of resentment (From Ranulf: 1964).

However, Scheler regards this as an exceptional example, and presents a theory of resentment in which "punitive moralizing" is regarded as a permanent mental attitude due to a systematic repression of certain emotions and impulses. Scheler describes resentment as "a spiritual self-intoxication." Resentment is called into existence by the presence of certain typical external situations, such as those in which oppressed social groups find themselves. The situations are those of powerlessness, and the feeling of inability to cope, such as that of an older generation which feels it cannot cope with the younger generation. This theoretical construct may also be applied to obscenity. If an individual is unable to cope with obscene stimuli either because of a lack of cultural norms which make the stimuli meaningful, or because of disordered personality, he would be inclined to punitive moralizing, or resentment. "Resentment," as Scheler uses it, differs substantially from the "anxiety" postulated in the current form of the sexual frustration propositions, however, and could be more accurately redefined as an indication of alienation or anomie (i.e. in terms of cultural inability to cope).

In personality theory most of the basic conceptions of reactions to obscenity have been stated in terms of psychological responses to obscene stimuli. The stimuli is presented, and if the respondent is threatened with releasing repressed desires he will show signs of anxiety (Freud, 1924). This invokes the imagery of a personality in equilibrium, with all its defenses and repressing devices in operation, which is threatened by disequilibration. Thus, an individual with exceptionally potent repressed desires, or with many repressions, would typically respond with anxiety. The sexual frustration hypothesis fits into this conception easily. A sexually frustrated individual would have to utilize various repressive mechanisms to achieve equilibrium, and these mechanisms would be threatened by any sexual stimuli. This type of view accords nicely with a cybernetic or systems theory of personality as well as with traditional psychiatric and psycho-analytic views.

Between these views, the sociocultural and psychoanalytic, there is obviously a great deal of disparity. Each is stated in a sufficiently vague manner as to the nature of the response and the processes as to preclude either easy empirical test or integration into more abstract schemes going beyond strict personality theory.

\section{The Response}

The first issue to be resolved in presenting a viable conceptual approach to the problem is to understand the response, or responses, to obscenity. Anxiety is perhaps a difficult concept to apply. Virtually any response, such as bewilderment, nausea, aggression, or resentment could be described as an anxiety response. Research utilizing such loose criteria would invariably confirm the "sexual frustration" hypothesis in terms of anxiety, but would certainly obscure other responses and explanations, such as those Scheler has suggested. The lax definition of anxiety utilized in psychotherapy often includes alienation and anomie (May, 1950). Conceptually, anomie, alienation, and anxiety involve different parts of an individual's situation, and all three may have bearing on the response to obscenity. 2 Different personality types or members of different cultural groups will respond differently. These are the differences which a concept of response 
must explain. The conceptual view may be taken that the three responses (anomle, alienation, and anxiety) constitute types of response to a situation. These types are analytically distinct, but have important systemic relations. 3 The individual responds to a situation according to various patterns. Normal situations, such. as public situations (office, supermarket, etc.) or interpersonal relations are dealt with according to certain beliefs (norms and perceptual tools), techniques of control, and the personality of the individual. These operate together to give the individual satisfaction. When an individual's beliefs, powers, or personality cannot cope with these ordinary situations to his satisfaction he adjusts the various elements. The beliefs and techniques of control or relating, develop with the situations the individual encounters. Certain situations or perceptions arise which are extraordinary; and to which the dynamic cannot properly respond. Obscenity may, for a given individual, be such an extraordinary perception. The perception does not involve simply the norms, or the personality, but the entire dynamic. Response to the situation of obscenity depends on the culture, personality, and means of control of the individual. For this reason what is "obscene" must be defined in terms of the stimuli's consequences for the dynamic rather than by any absolute standard.

For the "spirtually intoxicated" individual Scheler describes, inability to cope with obscenity is the same as his other inabilities to cope. The lack of techniques to cope, of power, permanently alters the entire dynamic, and the resentment response serves as the only response to changes in the individual's situation, attacks on his beliefs, or attacks on his personality. It is an example of means perverting ends; of resentment (in milder form, alienation), which is the means of coping, coming to govern the entire personal psychological and cognitive dynamic. Resentment does this by altering the belief and perceptual structure. The individual perceives that his only possible response is resentment, and that most stimuli are to be resented. The personal dynamic is, so to speak, short circuited.

This is an exceptional case. It does, however, raise some important questions. In this conception, the stimuli do not simply have consequences for the belief, normative and perceptual structure, or the personality structure, or the techniques of coping, but for the whole dynamic. Using this approach, we may differentiate between the little old lady who joins a league to prevent smut on television and a lady who does not, even though they may have the same personality and culture. The woman who joins the league has a technique of coping, the other woman does not. The first woman is likely to retain the same personality structure and culture, while the second woman may respond in several ways. She may change her standards of what is obscene (cultural change), or she may have a personality change. Of course all these structural changes will ramify into the other two structures in the dynamic. Individuals may be understood in their responses only comparatively, and the structures may be understood in this manner.

This conception effectively integrates the various viewpoints previously referred to, and provides a framework for empirical testing of specific propositions, such as the proposition that sexual frustration leads to anxiety responses to obscenity. While this conceptual viewpoint would regard this proposition as an oversimplification which fails to account for cultural factors which might turn the relationship either way, it could be discarded as not universal if, with cultural and other factors controlled, the relationship was not found to be positive.

\section{Methodological Problems}

Testing hypotheses in a systemic conceptual model is a subtle endeavor. A proposition like "anxiety reactions to mildly obscene stimuli are evidence of sexual 
frustration" involves three elements which are difficult to define in absolute terms, so must be tested in a ceteris paribus manner. It is difficult to tell exactly what factors are being held constant, especially outside of the laboratory. Furthermore there are no standard measures of "reactions," "obscene," or "sexual frustration."

The measurement of reactions to obscene stimuli is an extremely complex problem. If the measurement attempts simply to deal with "reactions," rather than any specific reaction, the problem of interpretation becomes insurmountable. Some of the recent work of "ethnomethodologists," such as Professor Harold Garfinkel of U.C.L.A. has been difficult to conceptualize in the abstract for this reason. Yet besides this and certain physiological indicators, virtually the only means of measuring reactions are tests which measure attitude change. Unfortunately there is no adequate theoretical model that places "attitudes" in a comprehensible conceptual position in relation to cognition or personality. Furthermore, the theoretical problem of reactions to obscenity is difficult to state in terms of attitude. Even if different attitudes could be correlated to sociological or personality indicators, this would tell little about the dynamics of the response, unless one were willing to assume that certain attitudes were evidence of anxiety. This assumption would perforce require a cultural definition of anxiety, rather than a psychological one. Anxiety would no longer be defined as a property of an individual personality, but could be the property of a culture or social system in which such attitudes inhered. This would clearly require extending the definition of anxiety unduly. It would not be conceptually improper to conceive of a society in which all individuals evidenced a great deal of anxiety. It would be as improper to conceive of a sub-culture or society whose attitudes are defined to be evidence of anxiety, than to conclude a fortiori that such a society was composed of anxious souls. The attitudes must be examined in terms of the personality and powers of the individuals of a given social group. Some attitudes may be unrelated to anxiety in another sub-culture. Moreover, the same attitudes may differ in their relation to anxiety from personality to personality. Attitude tests, therefore, may not deal with a proposition framed in the manner of our proposition about anxiety and frustration. Interviewer effects may cause some problems in interpretation as well. If the experimental subject is placed in a position where he has a role to play, or knows he has been selected for his playing of a given role, he may respond in terms of role expectations rather than in terms of his personal response. A housewife, for example, playing the role of a mother would respond differently than a housewife playing the role of a cocktail party bon vivant. These effects may be sidestepped by putting the subject in an ambiguous role situation. This may be effectively done by not letting the subject know that he is being compared to other experimental groups. If the experimental setting is depersonalized,interviewer effects may be obviated as well. The best results would probably be obtained by using a paper and pencil testing instrument rather than a face-to-face interview. Problems of evasive or misleading answers may also affect the results. Any questionnaire, the purpose of which is overly obvious, may elicit deceptive responses, particularly in terms of obscenity and anxiety, where the hypothesis we are examining has ever become popularized by the "advice to the lovelorn" columns of the daily newspaper. Lastly, the responses to a question must be scaled in such a manner as to permit comparison to other populations. Open ended responses, such as those with which psychotherapists typically deal, do not permit easy comparison between groups, nor are they typically amenable to statistical analysis.

For measuring reactions to obscenity in terms of anxiety the best instrument would be an impersonally administered questionnaire the responses to which may be 
scaled, with questions which may indirectly determine anxiety reactions to specific stimuli.

Measuring sexual frustration is not particularly easy. It is difficult to erect any criterion that can differentiate levels of frustration, particularly that can differentiate levels of frustration relative to particular cultural patterns. Objective criteria, such as frequency and nature of sexual relations or contacts, are impossible to interpret. Levels of sexuality differ from individual to individual, so some ratio would have to be obtained. Induction of sexual frustration under laboratory conditions is not practicable. The most workable solution is to find in society two populations with virtually identical social selection factors, so that differences not related to frustration may be controlled for, where one population is "frustrated" and one is not.

The problem of operationally defining obscene stimuli is strictly an issue of technique. Any arbitrary but consistent standard to differentiate categories of obscene or not obscene can be used as a baseline to compare two groups. A factor that must be accounted for is the medium in which the stimuli is presented. A study using photographs as stimuli may elicit responses on aesthetic or technical rather than on emotional grounds. The subject may be responding to the medium of photography rather than to the content of the photograph. Humor, literary obscenity, and other forms may evoke similar responses. A mixed approach, where several media are utilized with the same subject, would tend to mitigate the effects due to such response sets.

Empirical Work

An explanatory experiment testing the hypothesis that sexual frustration leads to anxiety reactions to obscenity has indicated that the hypothesis is not valid, ceteris paribus, in all cases. This experiment tested two groups of college men for their reactions to four classes of stimuli in five "media."

The test of anxiety employed was to ask the subject in reference to each stimuli, whether he would be embarassed to admit to a psychiatrist that he had some relation to the particular stimuli. A sample question was: "If you had written this on the wall of a men's room, would you be embarassed to admit this to a psychiatrist?" The respondent's answer was endorsement of a point on a 4-point scale from (1) I would be embarassed to admit it, to (4) I would not be embarassed to admit it. The subject was asked to play the role of a psychiatrist's client and to respond accordingly. It was assumed that embarassment in answering a psychiatrist's questions indicates anxiety about the topic which is being discussed, and it is this indication of anxiety which we have utilized.

To differentiate between sexually frustrated and not frustrated populations two campuses in the same state university system were selected. One is an engineering school with approximately five hundred women (including married women) among its eight thousand students. The other campus has a sex ratio of 2:1 (females:males) and is located in a town which also has two girls colleges. To minimize sociologic differences, only students in the engineering division of the second campus were sampled, and after several interviews with students and personnel of the two institutions it was decided that the selection factors for engineers in the two schools were identical. The students in the school with the high male sex ratio were designated as the sexually frustrated population. This was decided after observation of sexual patterns in the two schools. The university with the larger proportion of co-eds provides plentiful sexual contact, while the other provides considerably less. 
The obscene stimuli we selected were divided into four categories: Sexualdeviant, nondeviant-sexual, nonsexual-deviant, and nonsexual-nondeviant. Each category contained one example of each of five "media"--limericks, jokes, cartoons (with captions), examples from literature, and graffitti. A total of twenty stimuli were selected and randomly ordered on the questionnaire (to avoid response set). The stimuli were first presented to a panel of graduate student judges who assigned each stimulus to one of the four categories. Any stimuli that were not placed unanimously in the expected category were discarded and another from the same "medium". was put before the panel until all twenty types of stimulus were selected.

A questionnaire containing the twenty stimuli was administered to subjects in groups. A tape was first played to the group explaining the ostensible goal of the experiment as an attempt to find out what people conceal in a routine psychiatric interview. The subjects were told that they were selected because they would soon be competing for responsible positions in industry. A short example of a first psychiatric interview was included on the tape, and this was very ambiguous. A sample of twenty freshman and sophomore engineering students taking an introductory psychology course was obtained from the campus with the high male-female ratio and twenty-five engineering students taking introductory psychology were obtained from the other campus. The students were in the middle of the semester in these courses, and the dates for the experiment were set so that the students would not be affected by vacations or fraternity "party weekends." A question asking whether the home town of the student was larger than the state capitol (pop. 30,000) was included after the questions on the stimuli.

Table 1. Group Means of Summations of Five Responses scaled 1-4 (anxiety-no anxiety), by Type of Stimuli

\section{Categories of stimuli}

\begin{tabular}{l|cccc} 
& $\begin{array}{l}\text { Non-deviant } \\
\text { non-sexual }\end{array}$ & $\begin{array}{l}\text { Non-deviant } \\
\text { sexual }\end{array}$ & $\begin{array}{l}\text { Deviant } \\
\text { non-sexual }\end{array}$ & $\begin{array}{l}\text { Deviant } \\
\text { sexual }\end{array}$ \\
\hline Frustrated & 17.20 & 14.75 & 13.80 & 13.65 \\
Unfrustrated & 17.04 & 14.28 & 13.64 & 12.00 \\
Large Towns & 18.21 & 15.09 & 13.47 & 13.48 \\
Smal1 Towns & 16.77 & 14.09 & 13.37 & 11.77 \\
& & & & 14.82. \\
$\begin{array}{l}\text { Frustrated } \\
\text { Large }\end{array}$ & & 14.54 & 13.00 & 11.61 \\
$\begin{array}{l}\text { Unfrustrated } \\
\text { Smal1 }\end{array}$ & & 14.00 & 13.80 &
\end{tabular}

(Large town population greater than 30,000 ) Higher scores indicate lower anxiety levels. 
Results and Conclusions

The difference between urban-frustrated and rural-unfrustrated subjects was significant $p .05$ (two-tailed test) with a test of difference of means using the $t$ distribution (for $N$ 120). This suggests that the differences between frustrated and non frustrated students with urban and rural backgrounds would be significant with a larger sample.

This would lead one to conclude that anxiety reactions to obscene stimuli in certain circumstances may be negatively related to sexual frustration. This would be improper in terms of the Freud-Scheler conceptual scheme discussed above. However, it is clear that the hypothesis of positive relation is not generally true; that in some circumstances the reverse is true.

The specific circumstances which have determined the results of this experiment appear to be cultural. The frustrated students did not utilize the normative or aesthetic habits of mind which distinguish between deviant-sexual and other stimuli. The relation of the culture to the rest of the "frustrated" community is not at issue here, but that cultural differences should appear indicates the importance of sub-cultural variations for psychotherapeutic theory.

The evaluation of any research on "pornography" or "obscenity" is complicated by a variety of factors ignored in the psychoanalytic treatment of the subject. The most important is a very complex set of changes in the nature of smut and uses of media, occurring simultaneously with the dilution of various mythologies on sex due to the decline in influence and subsequent de-emphasis of religious antisexualism. The primary institution to which these changes may be traced is the scientific and medical view of sexuality (and of man) that has arisen within the last century. 4

This revision of sexual ideologies seems to have occasioned a need for a "culture of sexuality" to define and organize previously taboo areas of experience. It is important to note that in advanced non-western cultures, such as the Islamic world, there is a substantial culture of sex that is an integral part of the religious, philosophical, and literary tradition. For a variety of reasons, notably the influence of Pauline theology, this area of experience never became a part of western culture proper. 5

Western "pornography," as an artistic and literary genre, seems to be a response, both implicitly and explicitly, to the problem of defining a universal set of experiences into a new common set of meanings, which is not in conflict with scientific conceptions of these experiences.

Some note must be taken of differences in the nature of various types of pornography and their future cohesion into a western sexual culture. Edward Shils (1963) has divided culture into three types: refined, mediocre, and brutal. These distinctions apply informatively to sexual culture, and many seeming changes in the "definition of pornography" may be clarified in terms of these categories. On the brutal level of culture we find such male pornographic phenomenon as stag films, which have been around since the twenties: a type of repititious pornographic paperbacks, which have developed quite recently in the light of the "Tropic of Cancer" decision: 6 and the more recent "beaver" and "shaved beaver" films. Feminine "brutal" culture is expressed in the confession magazines, which have become increasingly explicit (Iverson: 1970), and certain television "soap operas." There is a significant common ground between males and females on this level, including tabloid newspaper and " $C$ " movies, typically shown in drivein theaters. 
On the mediocre level there is little common ground between the sexes. Male mediocre sexual culture includes the better "dirty books" and the "men's magazines." 7 Female mediocre sexual culture is quick to denounce male sexual culture, but is becoming paradoxically increasingly pornographic itself. The vehicle of feminine sexual culture on this level are the high circulation women's magazines. Until very recently, explicit sexual references, although common, were limited to medical exigesis, but fiction articles have become increasingly sexual. This represents in microcosm the historical tendency of scientific viewpoints uprooting earlier conceptions, requiring a culture of sex. For women's mediocre sexual culture the newer themes are increasingly present in best-seller books and Hollywood "nonarty" movies.

Refined culture is, by definition, traditional, and traditional forms of pornography, such as books "privately printed in Paris" still grace refined libraries and current literature has some effect, but the main vehicle for refined sexual culture is largely aesthetics and snobbery. Refined culture tends to be male on non-sexual phenomenon, and no feminine culture may be distinguished. However, grand bourgeois women may be expected to react in a somewhat Victorian manner to sexual and other cultures of lower levels.

The aesthetic issues seem to dominate criticism of other cultural levels, especially for women. Responses to obscenity and definitions of obscenity generally reflect these differences. A good example of sexual aesthetic stratification is bust size. Refined culture idollzes the small breast, mediocre culture the moderate breast, while brutal culture heavily emphasizes large breasts, both in low level men's magazines and in the confession magazines. The results of this study would seem to suggest that these cultural patterns are continuing to evolve, and that there is a lapse between the time cultural change occurs in urban areas and rural areas and small towns. The difference between the two campuses would seem to reflect the difference between "mediocre culture" males who are exposed to the viewpoints of "mediocre culture" women and those who are not. The males with contacts with women are inclined to distinguish deviant sexual stimuli from deviant non-sexual and non-deviant sexual stimuli, while students with few contacts are likely to make no distinction. Feminine mediocre culture, which seems to be the most Victorian category of sexual culture, is the culture of most college girls, and these girls serve as part of the "generalized other" of the engineering students on the campus with the low male-female ratio; while feminine culture is not present at all on the campus with the high male-female ratio.

The creation of a sociology of smut is not as frivolous a pursuit as it may initially appear. It would lead to a more complete understanding of the relation of sex to cultural patterns--a relation badly obscured by a naive sociological quasi-Freudianism. Anti-smut campaigns and crusades also constitute a recurrent but neglected social phenomenon too frequently swept under the same rug as the so-called "radical right," which deserve some study in their own right. The recent phenomenon of relatively explicit smut in women's magazine fiction (particularly of the confession magazines) would tend to indicate that Kinsey's assertion that "women have no interest in pornography" (1949) is not an adequate description of today's woman. An examination of "ladies' smut" could yield valuable understanding of the sociological and psychological meaning of smut, as well as of changing conceptions of sexuality. 


\section{Footnotes}

Acknowledgements to Russell Geen for many helpful suggestions and to William Murphy for his help in obtaining subjects.

${ }^{1}$ A study of Dallas Right-wingers by Alan C. Elms (1970) Indicates a lack of empirical support for the thesis that right-wingers are crackpots.

2 We may define anomie as "normlessness," alienation as "powerlessness," anxiety as "the losing of self," and we may suggest that anomie results from norms and cultural patterns that do not make the situation of the individual meaningful, alienation results from the lack of individual ability to manipulate his situation, and anxiety results from an individual's inability to relate his "self" to his "situation."

3 Speaking of a "system" or "dynamic," or of dividing this "system" into three elements is only a methodological ploy with no epistemological implications. The conception would best be stated in terms of "institutions" in Veblen's sense, of habits of mind. Viewed in this manner particular recurrencies of action may be explained in terms of the relations between the habits of mind of various individuals. Clearly, institutions may well cross the lines of the three categories of personallty, culture, and means of control. Recurrent responses like Scheler's resentment would be conceptualized as institutions, as would alienation, anomia, and anxiety. This would avoid the considerable difficulties of equilibrium or balance personality theories as well as avoid the disposition to conceive of anxiety, anomia, and alienation as abnormal, and therefore tainted. However, the Veblenian epistemology does not yield broad generalizations such as the one to which this paper is addressed, and sociologists are wont to pursue.

${ }^{4}$ It must be realized that it has not been long since respected physicians endorsed the view that masturbation was the leading cause of insanity. The centrality of these changes in belief to the changes in sexual patterns has not been lost on fundamentalist Protestant leaders. Billy Graham, for example, wrote an article identifying sex research with the devil in the 1950 's and current radio evangelists utilize the same theme. It is this revised conception that coincides essentially with the heralded revolution in sexual ethics and mores. It suggests that many of the supposed normative changes reflect the freeing of sexuality from folk conceptions of sex rather than some underlying change in western morals. For a comparative example, in Sweden, where pornography is most widespread, folk conceptions of sex have been most vigorously eradicated.

${ }^{5}$ With notable exceptions, such as The Decameron of Boccaccio, which was, however, a conscious attack on institutions of the time, particularly the Church.

6 The "dirty book" business on a mass scale is a relatively recent phenomenon. The innovation can be credited to Maurice Girodias and the Olympic Press, which first published the works of an impressive segment of the American literary elite in Paris. As the "dirty book" business opened up much inferior pornography flooded the market, and the "brutal" level of sexual culture includes most of this third rate material. 
${ }^{7}$ It is interesting to note that the leading example of this genre, Playboy, has explicitly attempted to promulgate a new sexual culture in its "Playboy Philosophy."

\section{References}

Edwardes, Allen and R.E.L. Masters

1962 The Cradle of Erotica. New York: The Julian Press, Inc.

Elms, Alan C.

1970 "Right Wingers in Dallas." Psychology Today, Vo1. 3, No. 9 (February): 27-31.

Freud, Sigmund

1936 The Problem of Anxiety. H.A. Bunker (trans.). New York: W.W. Norton \& Co., Inc.

Garfinkel, Harold

1967 Studies In Ethnomethodology. Englewood-Cliffs, N.J.: PrenticeHall, Inc.

Firodias, Maurice

1967 The Olympia Reader. New York: Ballantine Books.

Iverson, William

1970 Venue US.A. New York: Simon and Schuster, Inc.

May, Ro110

1950 The Meaning of Anxiety. New York: The Ronald Press Company.

Ranulf, Svend

1964 Moral Indignation and Middle Class Psychology. New York: Schocken Books.

Shils, Edward A.

1954 "Authoritarianism: 'right' and 'left'." Pp. 24-49 in R. Christie and M. Jahoda (Eds.), Studies in the Scope and Method of "The Authoritarian Personality". Glencoe, I11.: Free Press.

1963 "Mass Society and its Culture.". Pp. 232-260 in H.M. Ruitenbeek (ed.), Varieties of Modern Social Theory. New York: E.P. Dutton \& Co., Inc. 